\title{
NANOCOMPOSITES COMPRISING CELLULOSE AND NANOMAGNETITE AS HETEROGENEOUS CATALYSTS FOR THE SYNTHESIS OF BIODIESEL FROM OLEIC ACID
}

\author{
Helmiyati $^{1 *}$, Yossy Anggraini ${ }^{1}$ \\ ${ }^{1}$ Department of Chemistry, Faculty of Mathematics and Natural Sciences, Universitas Indonesia, \\ Kampus UI Depok, Depok 16424, Indonesia
}

(Received: November 2018 / Revised: February 2019 / Accepted: April 2019)

\begin{abstract}
A nanocomposite comprising cellulose and nanomagnetite based on rice husk cellulose was used as the catalyst for the formation of methyl esters from oleic acid as an alternative method for biodiesel production. The resulting nanocomposite properties supported by FTIR, XRD, SEM and TEM characterization revealed that nanomagnetite $\mathrm{Fe}_{3} \mathrm{O}_{4}$ had impregnated the acetylated nanocellulose. The nanomagnetite $\mathrm{Fe}_{3} \mathrm{O}_{4}$ obtained had an average size of $30 \mathrm{~nm}$. The best conversion of oleic acid to methyl esters for the catalytic application of the nanocomposite was $89.21 \%$, which was achieved at a reaction temperature of $60^{\circ} \mathrm{C}$, reaction time of 5 hours, catalyst concentration of $1.5 \mathrm{wt} . \%$, and ratio of oleic acid to methanol of 3:1. Kinetic analysis at different temperatures $\left(40,50,60\right.$ and $\left.70^{\circ} \mathrm{C}\right)$ was performed, and a low activation energy of $16.56 \mathrm{~kJ} / \mathrm{mole}$ was obtained. These results indicate that the biopolymer-based nanocomposite utilizing nanocellulose from rice husks composited with inorganic $\mathrm{Fe}_{3} \mathrm{O}_{4}$ nanoparticles has good potential for use as a green biocatalyst, and the proposed reaction can be used as an innovative new method to produce biodiesel in the future.
\end{abstract}

Keywords: Catalyst; Cellulose; Magnetite; Methyl esters; Nanocomposite

\section{INTRODUCTION}

Biodiesel is an alternative fuel that can substitute for petroleum diesel fuel; it is produced through chemical reactions from triglyceride fatty acids that are not derived from petroleum. Compared to fossil fuels, biodiesel is a promising alternative due to its renewable properties, greenhouse gas reduction, biodegradable properties, nontoxicity, sulfur-free gas emissions and environmental friendliness (Veillette et al., 2017). Biodiesel functions in a similar way to petroleum diesel, but produces significantly less air pollution and is safe for the environment (Degife et al., 2015).

One method to produce biodiesel is by the esterification and transesterification reactions of fatty acids. Esterification and transesterification are important organic reactions between fatty acids or triglycerides and low-chain alcohols, which produce esters in the presence of a catalyst. The fatty acids and triglycerides that are used can be derived from vegetable oils or animal fats, such as free fatty acids (El-Nahas et al., 2017). Currently, biodiesel is produced commercially using homogeneous catalysts such as sulfuric acid and sodium hydroxide as these strong acids or bases have high catalytic activity and low cost. However, the use of a homogeneous catalyst in the catalytic process of transesterification causes the reaction to become corrosive and will also

\footnotetext{
*Corresponding author's email: helmi-yt@ui.ac.id, Tel. +62-21-7270027, Fax.+62-21-7863432

Permalink/DOI: https://doi.org/10.14716/ijtech.v10i4.2597
} 
produce acidic or basic waste from the homogeneous catalyst (Colombo et al., 2017).

Recently, the catalysts used have been replaced with more environmental friendly heterogeneous ones (Caetano et al., 2013; Mendonça et al., 2019). The catalysis process using heterogeneous catalysts is great interest because it has beneficial characteristics such as high selectivity, long catalyst life, easy recovery, repeatability, and temperature stability; the catalyst can also be easily separated from the reaction mixture (Climent et al., 2012; Santos et al., 2015). Among such heterogeneous catalysts, considerable research has been conducted using inorganic substances such as $\mathrm{Fe}_{3} \mathrm{O}_{4}, \mathrm{CaO}, \mathrm{Al}_{2} \mathrm{O}_{3}$ and $\mathrm{MgO}$. However, if the inorganic catalyst is not modified, it will have low thermal stability and solubility in water; for example, an unmodified $\mathrm{Fe}_{3} \mathrm{O}_{4}$ catalyst is reversible, causing an unstable reaction. Therefore, several studies have focused on developing procedures for nanocomposite synthesis using biopolymers as a support (Sabaqian et al., 2016). Biopolymers such as cellulose have the potential to be used as supporting substances in heterogeneous catalysis (Eyley et al., 2014; Arantes et al., 2017).

Cellulose is one of the most abundant and renewable natural polymers; approximately $10^{11}-10^{12}$ tons per year can be obtained from plants and it has been widely studied worldwide in academic and industrial research (Ummartyotin \& Manuspiya, 2015). It is a carbohydrate polymer consisting of repeating units of $\beta$-D-glucopyranose, comprising three hydroxyl groups in each of its anhydro-d glucose units, meaning the cellulose molecule has great $\mathrm{OH}$ functionality (Lavoine et al., 2012). Cellulose can be converted into nanocellulose, which acts as a sustainable nanomaterial because of its availability, biodegradability and biocompatibility, because the materials produced from nanocellulose can be highly porous. Nanotechnology involving cellulose substrates has become a major focus of research because of the exceptional physical and chemical properties of nanocellulose. It has the potential to be used as an efficient support material because it can form bonds with several functional groups to produce heterogeneous catalysts based on biopolymers (Ummartyotin \& Manuspiya, 2015; Jabasingh et al., 2016).

However, the larger the number of $\mathrm{OH}$ functional groups, the greater the number of inter-or intramolecular hydrogen bonds, making cellulose less attractive as a catalyst-supporting substance. This can be avoided by modifying the cellulose surface so that the number of active sites will increase and efficiency will be higher (Habibi, 2014; Fatona et al., 2018). Modification of the cellulose surface functionalization can be made by acetylation (Sun et al., 2016) or phosphorylation (Wanrosli et al., 2013), among other processes. Functionalized nanocellulose combined with inorganic nanoparticles can form superior nanocomposites (El-Nahas et al., 2017)

In this study, cellulose is derived from rice husks, which have a large cellulose content (Helmiyati et al., 2017). We converted the cellulose to nanocellulose by mechanical ball milling, whereas previous studies used chemical methods (Nahas et al., 2017), and then acetylated it with anhydrous acetate to functionalize the surface. Subsequently, the acetylated nanocellulose was impregnated with magnetite iron oxide nanoparticles $\left(\mathrm{Fe}_{3} \mathrm{O}_{4}\right)$ to form a nanocomposite. The aim of the study is to evaluate the catalytic efficiency of these cellulose-magnetite nanocomposites as applied to the synthesis of methyl ester biodiesel from oleic acid. The reaction kinetics of the methyl ester synthesis from oleic acid were studied by observing the unreacted oleic acid concentration, and in order to determine the activation energy value the effect of temperature on the reaction was observed. 


\section{METHODS}

\subsection{Material}

The cellulose from rice husks is in accordance with its use in previous research (Helmiyati et al., 2017). Anhydrous acetate (Merck) was used for the synthesis of acetylated nanocellulose, while iron(III) chloride), iron(II) sulfate (Sigma Aldrich) and $\mathrm{NH}_{4} \mathrm{OH}$ (Merck) were used as materials for the synthesis of nanomagnetite. Oleic acid 90\% (Sigma Aldrich) and methanol (Sigma Aldrich) were used as methyl ester synthesis reagents.

\subsection{Preparation of Acetylated Nanocellulose}

The cellulose was modified into nanocellulose using a mechanical ball mill, and was then functionalized by using anhydrous acetate to form acetylated nanocellulose (Sun et al., 2016; Nahas et al., 2017) with slight modification. An amount of nanocellulose in deionized water was mixed with a magnetic stirrer for 1 hour at room temperature at $\mathrm{pH} 8$ by adding $\mathrm{NaOH}$. $25 \mathrm{~mL}$ of anhydrous acetate $(2.5 \%)$ was then added and stirred for 1 hour, with the addition of $\mathrm{HCl}$ to acid condition ( $\mathrm{pH} \mathrm{4.5).} \mathrm{The} \mathrm{solution} \mathrm{was} \mathrm{filtered} \mathrm{and} \mathrm{then} \mathrm{dried} \mathrm{by} \mathrm{freeze} \mathrm{drying} \mathrm{for} 24$ hours, whereas previous research has used an oven. The obtained acetylated nanocellulose was then characterized by FTIR, XRD, SEM and TEM.

\subsection{Preparation of Nanocomposites from Acetylated Nanocellulose and Magnetite $\mathrm{Fe}_{3} \mathrm{O}_{4}$}

The synthesis of nanocomposite refers to previous studies (Zarei et al., 2018). An amount of acetylated nanocellulose added to $\mathrm{FeSO}_{4} \cdot 7 \mathrm{H}_{2} \mathrm{O}(4.17 \mathrm{~g})$ and $\mathrm{FeCl}_{3} \cdot 6 \mathrm{H}_{2} \mathrm{O}(8.1 \mathrm{~g})$ and this mixture was placed into a round-bottom flask equipped with a reflux. $\mathrm{NH}_{4} \mathrm{OH}$ was then added to the mixture to obtain a $\mathrm{pH}$ of 11 . After the reaction was complete, the mixture was washed several times with water and ethanol, and the precipitation process was conducted with an external magnetic field. Furthermore, the nanocomposites were dried by freeze drying and then characterized by FTIR, XRD, SEM and TEM.

\subsection{Activity of the Catalyst and Analysis of Oleic Acid Conversion into Biodiesel}

The catalytic activity of the cellulose-nanomagnetic nanocomposites was monitored for the oleic acid esterification reaction with methanol (El-Nahas et al., 2017; Veillette et al., 2017). This work was performed by varying four parameters: the catalyst weight $(0.5-2.5 \mathrm{wt} \%)$, temperature (40, 50,60 and $\left.70^{\circ} \mathrm{C}\right)$, reaction time $(1-6$ hours) and the mole ratio of the reactants, while the amount of oleic acid was fixed and that of methanol varied (1:1, 1:2, 1:3, 1:4, and 1:5). Determination of the unreacted oleic acid concentration was made by the acid titration method, with $\mathrm{KOH}$ as the base. The acid value could then be calculated, the conversion of free fatty acids (FFA) determined (Hebbar et al., 2018), and characterization made of the methyl ester product by GC-MS QP2010 Plus with a polar column.

\subsection{Kinetic Studies and Determination of Activation Energy}

Kinetic studies were conducted by observing the unreacted oleic acid for 60 minutes with an interval of 10 minutes. The kinetic was then determined using first order equations and the effect of temperature on the reaction kinetics was observed.

\section{RESULTS AND DISCUSSION}

\subsection{Synthesis of Acetylated Cellulose -Nanomagnetite $\mathrm{Fe}_{3} \mathrm{O}_{4}$ Nanocomposites}

The nanocellulose was functionalized to increase the number of active groups, surface area and catalytic efficiency by acetylation using anhydrous acetate to form acetylated nanocellulose. This was composited with $\mathrm{Fe}_{3} \mathrm{O}_{4}$ precursors, in which the $\mathrm{Fe}^{2+}$ and $\mathrm{Fe}^{3+}$ ions will interact with the $\mathrm{OH}$ groups on the nanocellulose chain. The $\mathrm{OH}$ groups will act as a capping agent or stabilizer so that the nanoparticles formed will not agglomerate, and the particle size can be controlled. The 
addition of $\mathrm{NH}_{4} \mathrm{OH}$ will form $\mathrm{Fe}_{3} \mathrm{O}_{4}$ nanoparticles in the nanocellulose. An illustration of the formation of cellulose-nanomagnetite $\mathrm{Fe}_{3} \mathrm{O}_{4}$ nanocomposites is shown in Figure 1.

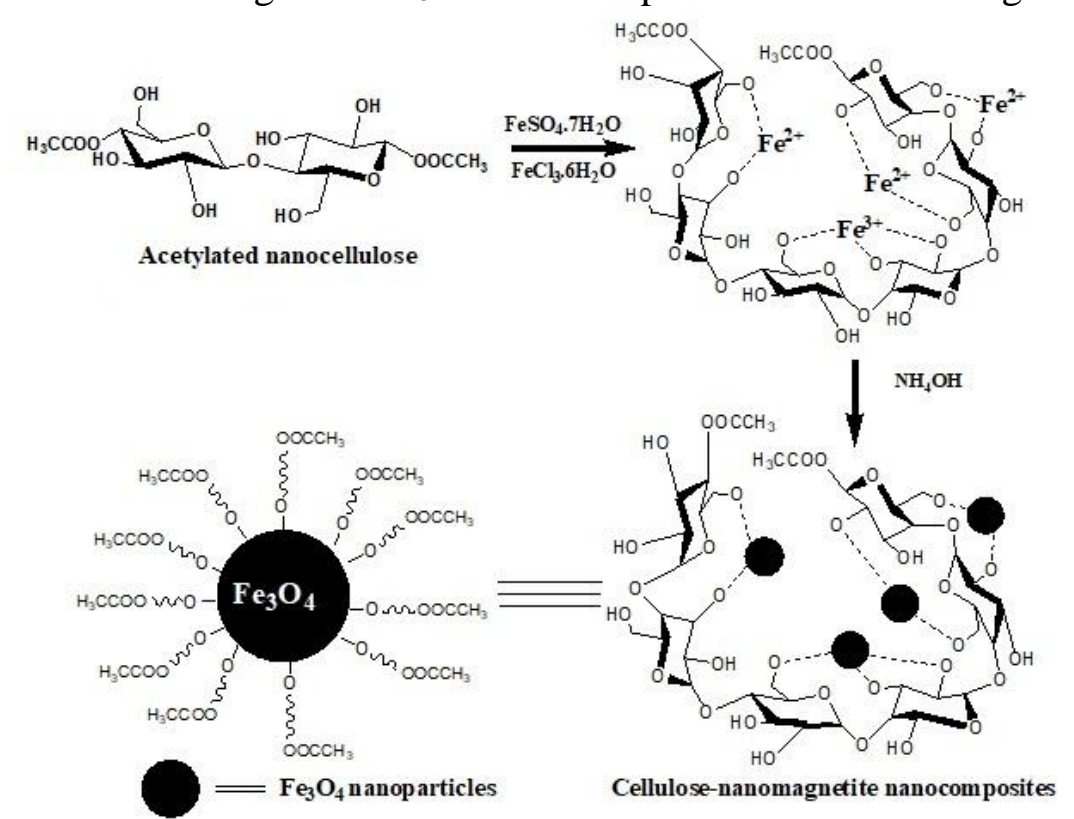

Figure 1 Illustration of cellulose-nanomagnetite $\mathrm{Fe}_{3} \mathrm{O}_{4}$ nanocomposites formation

\subsection{Characterization of Nanocomposites}

\subsubsection{FTIR analysis}

The FTIR spectra of the acetylated nanocellulose can be seen in Figure 2a, with the peak at approximately $900 \mathrm{~cm}^{-1}$, showing the main absorption band of the $\mathrm{C}_{1}-\mathrm{O}-\mathrm{C}_{4} \beta$-glycoside bond, which is typical of cellulose, and the C-O-C stretching vibration at approximately $1050 \mathrm{~cm}^{-1}$. The $\mathrm{O}-\mathrm{H}$ bending vibration is at approximately $1650 \mathrm{~cm}^{-1}$, the $\mathrm{C}-\mathrm{H}$ stretching vibration is at approximately $2890 \mathrm{~cm}^{-1}$ and the $\mathrm{OH}$ functional group stretching vibration is at $3300-3400 \mathrm{~cm}^{-}$ 1 . Figure $2 \mathrm{~b}$ shows the FTIR spectra of magnetite, indicating the main absorption band of the Fe$\mathrm{O}$ bond at approximately $600 \mathrm{~cm}^{-1}$, which is typical of $\mathrm{Fe}_{3} \mathrm{O}_{4}$ nanoparticles (Sabaqian et al., 2016). Figure 2c shows that the FTIR spectrum of the cellulose-nanomagnetite nanocomposite has similarities to the spectra of acetylated nanocellulose. When magnetite nanoparticles are combined with nanocellulose, the Fe-O peak shifts to $595 \mathrm{~cm}^{-1}$ and slightly widens due to the occurrence of Fe-O bonds on the surface of the nanocellulose, as illustrated in Figure 1.

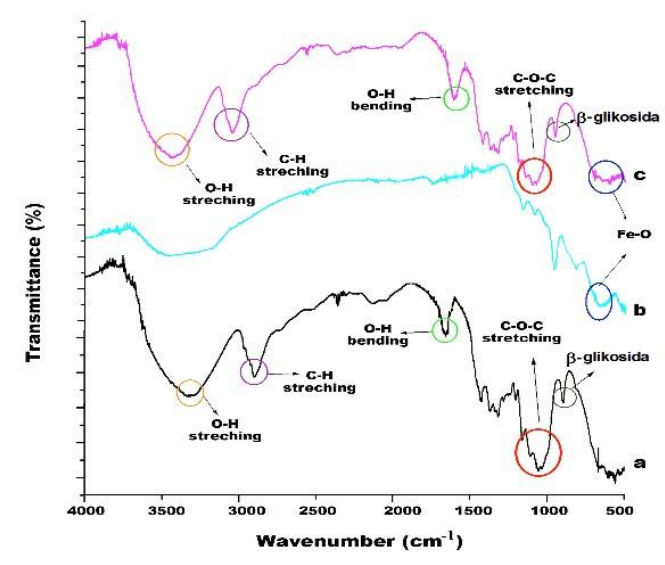

Figure 2 FTIR spectra of: (a) acetylated nanocellulose; (b) magnetite $\mathrm{Fe}_{3} \mathrm{O}_{4}$; (c) nanocomposites of cellulose magnetite

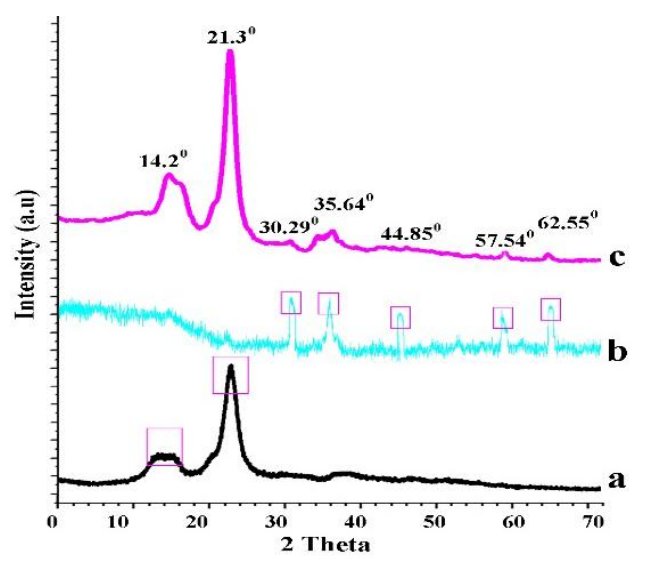

Figure 3 XRD diffraction patterns of: (a) acetylated nanocellulose; (b) magnetite $\mathrm{Fe}_{3} \mathrm{O}_{4}$; (c) nanocomposites of cellulose magnetite 


\subsubsection{XRD analysis}

XRD characterization was performed on the acetylated nanocellulose, magnetite $\mathrm{Fe}_{3} \mathrm{O}_{4}$ and compared to the nanocomposites of cellulose magnetite, as shown in Figure 3. Figure 3a shows that the diffraction patterns of acetylated nanocellulose have a sharp peak at $21.3^{\circ}$ and a weak peak at $14.2^{\circ}$, which is characteristic of cellulose, which usually has a peak at around $22.4^{\circ}$ called the intensity of crystalline, and peak at $18.25^{\circ}$ called the intensity of amorphous (Helmiyati et al., 2017). Figure $3 \mathrm{~b}$ shows that the $\mathrm{Fe}_{3} \mathrm{O}_{4}$ nanoparticles have five peaks at $30.20^{\circ}, 35.50^{\circ}, 43.10^{\circ}$, $57.00^{\circ}$ and $62.60^{\circ}$. These results correspond well with a study conducted by Sabaqian et al. (2016). Figure $3 \mathrm{c}$ shows that the diffraction pattern of nanocomposites made of cellulose and magnetite have diffraction peaks at approximately $14.2^{\circ}$ and $21.3^{\circ}$, both of which are characteristic of cellulose (Helmiyati et al., 2014), with peaks also appearing at $30.29^{\circ}, 35.64^{\circ}$, $44.85^{\circ}, 57.54^{\circ}$ and $62.55^{\circ}$, which correspond to five $\mathrm{Fe}_{3} \mathrm{O}_{4}$ nanoparticle peaks. This shows that the $\mathrm{Fe}_{3} \mathrm{O}_{4}$ nanoparticles have been composited with the nanocellulose surface, which is supported by the FTIR results in Figure 2.

\subsubsection{SEM analysis}

The surface morphology from the SEM characterization is shown in Figure 4. In Figure 4a, that of acetylated nanocellulose shows homogeneous, subtle and short fibrils, while Figure 4b shows the cellulose-nanomagnetite nanocomposite with fibrils, which are characteristic of nanocellulose. In addition, spherical $\mathrm{Fe}_{3} \mathrm{O}_{4}$ nanoparticles can be seen on the surface of the nanocellulose (circled in red). This result is supported by the XRD diffraction pattern in Figure 4.

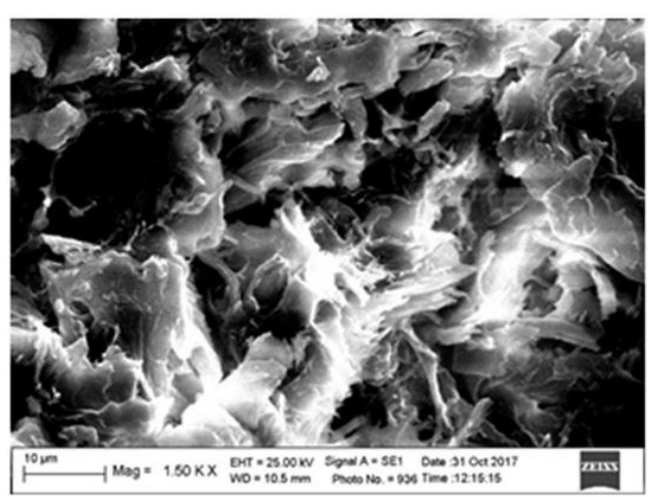

(a)

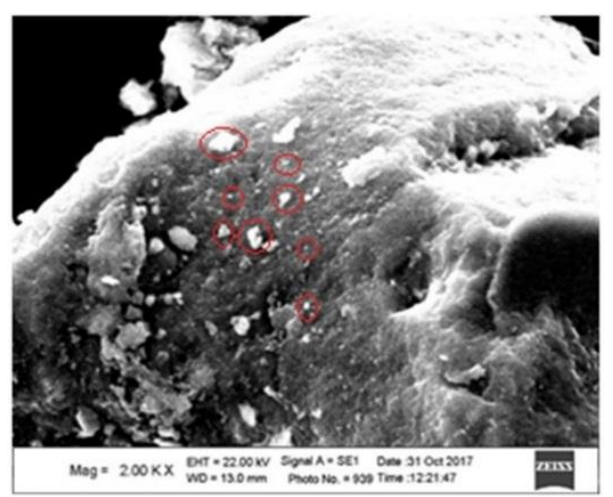

(b)

Figure 4 (a) SEM micrographs of acetylated nanocellulose at 1000x magnification; (b) nanocomposites of cellulose and nanomagnetite $\mathrm{Fe}_{3} \mathrm{O}_{4}$ at 2000x magnification

\subsubsection{TEM analysis}

The TEM characterization results are shown in Figure 5. Figure 5a shows the surface morphology of acetylated nanocellulose with a scalebar of $100 \mathrm{~nm}$. The acetylated nanocellulose shows a smooth and homogeneous morphology, with the fibers are clearly visible, together with short fibrils with an average size of around $165 \times 25 \mathrm{~nm}$ (circled in green). Figure $5 \mathrm{~b}$ shows the surface morphology of the cellulose-nanomagnetite $\mathrm{Fe}_{3} \mathrm{O}_{4}$ nanocomposite with a scalebar of $100 \mathrm{~nm}$. The small dark-colored spots are nanomagnetite $\mathrm{Fe}_{3} \mathrm{O}_{4}$, with an average size of around $30 \mathrm{~nm}$ (circled in red), and located on the surface of the nanocellulose, which is lighter in color. This indicates that nanomagnetite $\mathrm{Fe}_{3} \mathrm{O}_{4}$ was successfully composited with the acetylated nanocellulose as a support material. This result is supported by the previous characterization, which can then be used as a catalyst. 


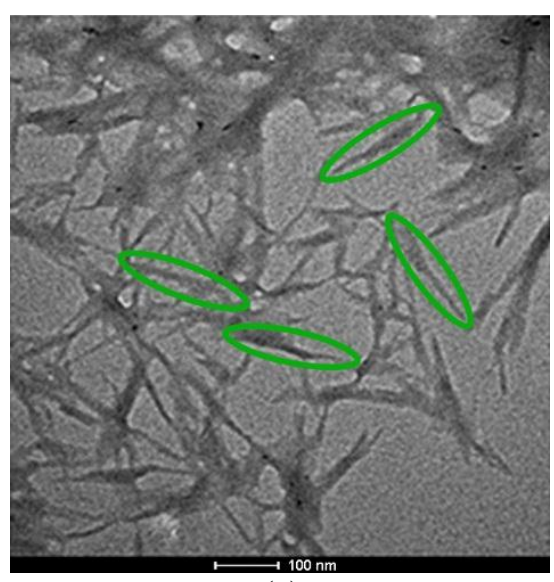

(a)

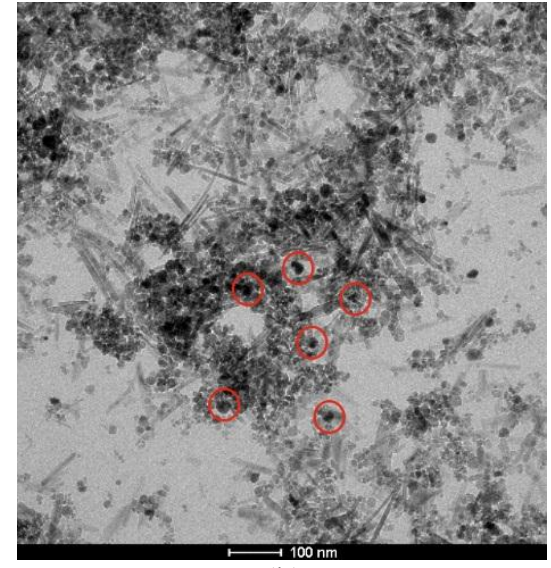

(b)

Figure 5 TEM micrographs of (a) acetylated nanocellulose $100 \mathrm{~nm}$ scale; (b) cellulose-nanomagnetite $\mathrm{Fe}_{3} \mathrm{O}_{4}$ nanocomposites $100 \mathrm{~nm}$ scale

\subsection{Catalytic Activity for the Synthesis of Methyl Ester Biodiesel from Oleic Acid}

\subsubsection{Effect of nanocomposite catalyst concentration}

Figure 6 shows that with increasing catalyst concentration, conversion of the product also increases. This is due to the increased concentration of catalysts, meaning that there are more active sites, which will increase the number of activated complexes of the nanocomposites and the level of oleic acid, the impact of which is an increase in methyl ester product. However, when the concentration of catalysts was increased to $2.5 \mathrm{wt} . \%$, there was no significant increase in conversion. In this work, the maximum amount of catalyst is $1.5 \mathrm{wt} . \%$. The use of nanocomposite catalysts comprising cellulose biopolymer and nanomagnetite in this study was more effective than those used by Hidayat et al. (2018), namely zeolite impregnated with potassium nitrate. They obtained an optimum amount of catalyst of $5 \mathrm{wt} . \%$.

\subsubsection{Effect of reaction temperature}

Figure 7 show with that an increase in temperature to $60^{\circ} \mathrm{C}$ the conversion also rises; kinetically, the higher the temperature, the greater the number of collisions between particles, and the reaction rate will also increase, so the amount of resulting product increases. In this work, the optimum temperature for methyl ester formation was $60^{\circ} \mathrm{C}$. A similar result was obtained by Cercado et al. (2018) using homogeneous catalysts. However, when the temperature was raised to $80^{\circ} \mathrm{C}$, the conversion tended to decrease. This was due to the boiling point of methanol being approximately $65^{\circ} \mathrm{C}$, so it was possible to evaporate the methanol before it could react with the oleic acid, meaning conversion decreased.

\subsubsection{Effect of reaction time}

Figure 8 shows that an increase in reaction time will increase the conversion, as an increase in time will increase the number of activated complexes that form between the reactants and the catalyst. The optimum reaction time was obtained at 5 hours. This is longer than that of Hidayat et al. (2018) of 4 hours with a biodiesel yield of $83.2 \%$; however, the conversion yield of this study is $89.2 \%$. When the reaction time was increased to 6 hours, the conversion decreased because the transesterification reaction produces water byproducts, meaning the reaction is likely to undergo a reversible reaction with the longer reaction time.

\subsubsection{Effect of reactant mole ratio}

Figure 9 shows that with an increase in the amount of methanol conversion also rises, because excess methanol in the reaction will shift towards the formation of products. The optimum conversion of $89.21 \%$ was obtained with a $1: 3$ ratio of oleic acid to methanol. However, with excess methanol (1:4 or higher), conversion decreased, due to the possibility of excess methanol 
producing byproducts. Using heterogeneous nanocomposite catalysts in this study produced better results than Cercado et al. (2018), who employed homogeneous catalysts and obtained anoptimum ratio of microalgae to oil of 1:12.

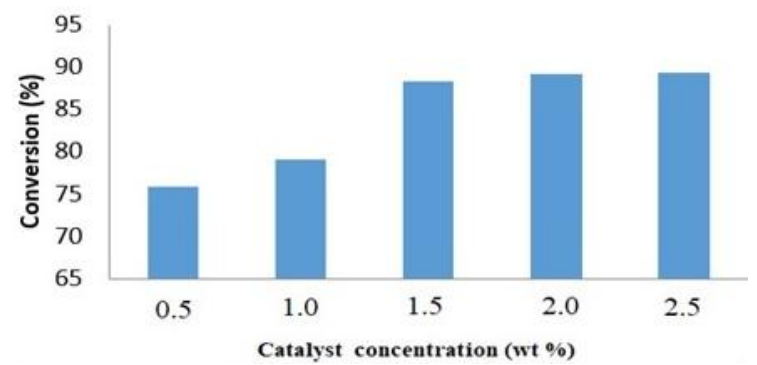

Figure 6 Effect of catalyst concentration

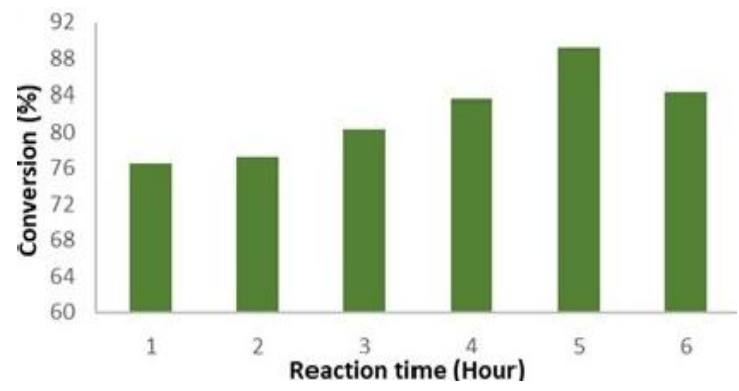

Figure 8 Effect of reaction time

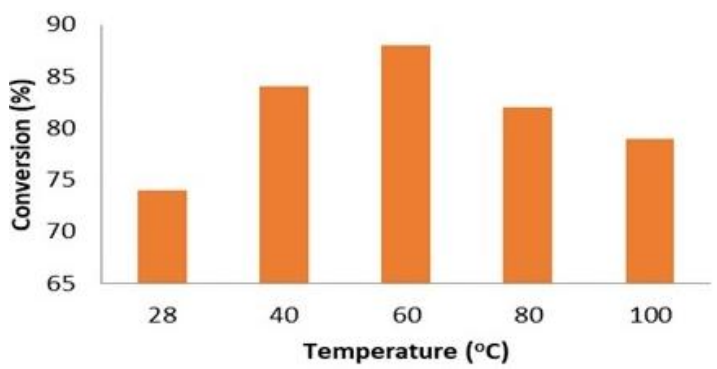

Figure 7 Effect of reaction temperature

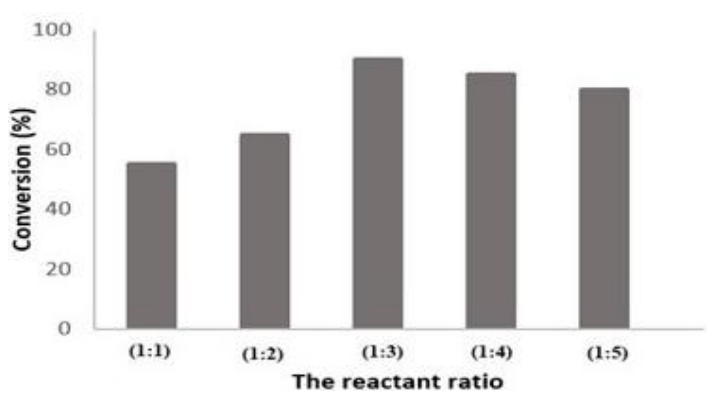

Figure 9 Effect of reactant ratio

The catalytic activity for the synthesis of methyl ester from oleic acid obtained the highest conversion of $89.21 \%$, with a catalyst weight of $1.5 \%$ by weight, reaction temperature of $60^{\circ} \mathrm{C}$, reaction time of 5 hours, and lower ratio of oleic acid to methanol of 1:3.

\subsubsection{Analysis of methyl esters using GC-MS}

The formation of methyl esters was characterized using GC-MS to determine the type formed. Methyl ester synthesis was conducted under optimum conditions for high conversion (catalyst weight $1.5 \mathrm{wt} \%$, reaction temperature $60^{\circ} \mathrm{C}$, reaction time 5 hours, and ratio of oleic acid to methanol 1:3). Figure 10 shows the GC-MS results is plot of relative abundance (\%) to mass to charge ratio (m/z). The peaks at $264.1\left(\mathrm{M}^{+}-32\right)$ and $222.2 \mathrm{~g} / \mathrm{mol}_{(}\left(\mathrm{M}^{+}-74\right)$, amongst others, are ion fragments formed before the methyl ester compound $\left(\mathrm{M}^{+}\right)$was formed.

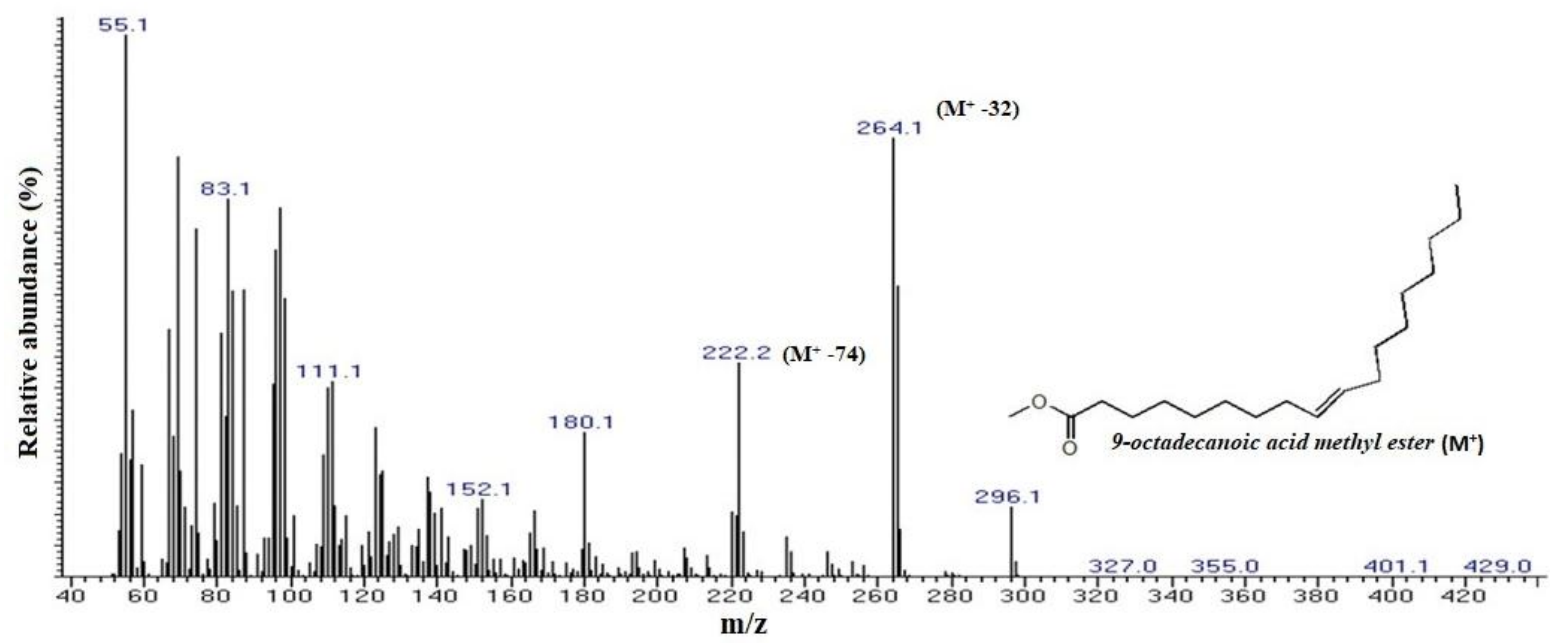

Figure 10 Results of methyl esters with GC-MS 
The type of methyl ester formed as the product is a 9-octadecanoic acid methyl ester compound with a relative molecular mass of $296.1 \mathrm{~g} / \mathrm{mol}$.

\subsection{Study of the Reaction Kinetics of Methyl Ester Formation from Oleic Acid}

The esterification reaction of oleic acid with methanol to produce methyl ester can be represented by the following reaction, Equation 1:

$$
\text { Oleic Acid + Methanol } \rightarrow \text { Methyl Ester + Water }
$$

The reaction uses excess methanol so that the reaction kinetics model becomes Pseudo first order, as shown in Equation 2:

$$
\operatorname{Ln}[O A]_{t}=\operatorname{Ln}[O A]_{0}+k d t
$$

where $[\mathrm{OA}]_{\mathrm{t}}$ and $[\mathrm{OA}]_{0}$ represent oleic acid concentration at a certain time and initial time respectively. The plot of $\mathrm{Ln}[\mathrm{OA}]_{\mathrm{t}}$ to time $\mathrm{t}$ can be seen in Figure 11; the slope was calculated to determine the rate constant, which depends on the reaction temperature. In Figure 11, it is shown that increasing temperatures of $40,50,60$ and $70^{\circ} \mathrm{C}$ will increase the reaction rate constant from $0.0095,0.0112,0.0137$ and $0.0165 \mathrm{~min}^{-1}$ respectively. This constant $(k)$ depends on temperature, according to the Arrhenius equation shown below in Equation 3:

$$
\operatorname{Ln} k=\operatorname{Ln} A-\frac{E_{a}}{R T}
$$

To determine the activation energy of the transesterification reaction for the synthesis of methyl ester from oleic acid, $\ln k$ vs $1 / \mathrm{T}$ was plotted, with the slope of the graph equal to $\mathrm{Ea} / \mathrm{R}$. The plot of $\ln k$ vs 1/T for the temperature variations can be seen in Figure 12.

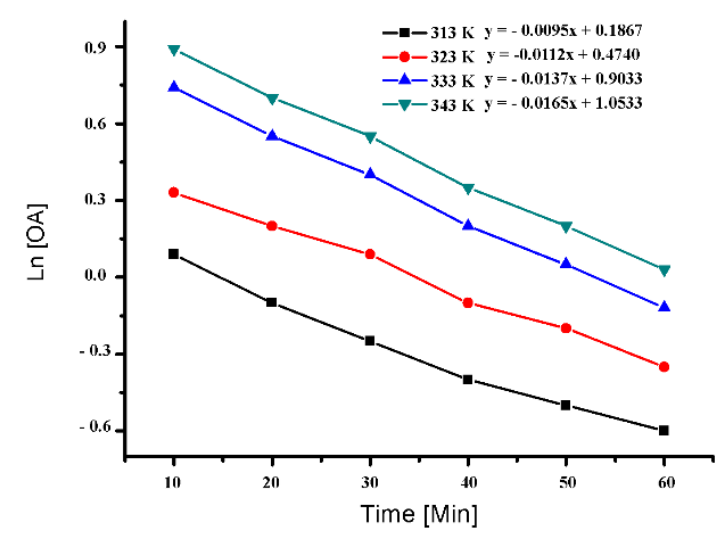

Figure 11 Plot of $\mathrm{Ln}[\mathrm{OA}]_{\mathrm{t}}$ to time

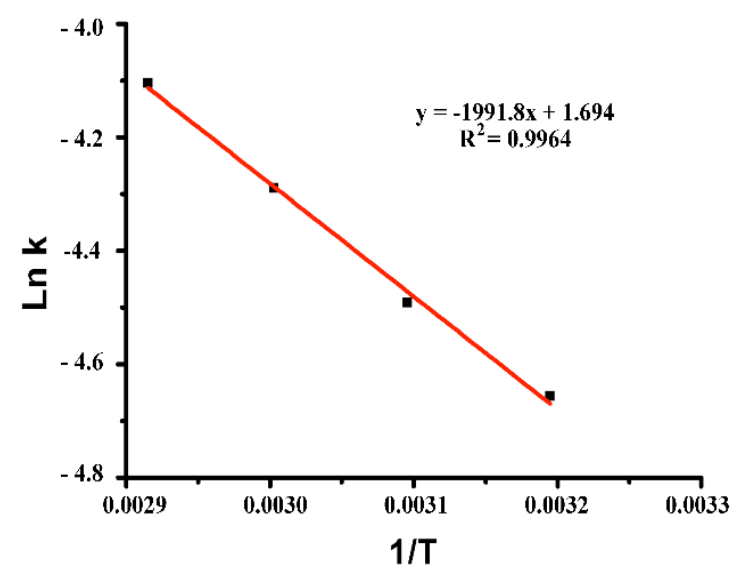

Figure 12 Plot of $1 / \mathrm{T}$ to $\ln k$

In Figure 12, the slope of line (-Ea/R) is 1991.8 , so the activation value of methyl ester formation from oleic acid is $16.56 \mathrm{~kJ} / \mathrm{mol}$. The results of the kinetic study in this experiment compare with similar work from other researchers, as shown in Table1.

Table 1 Review of kinetic studies of transesterification reactions

\begin{tabular}{llccc}
\hline \multicolumn{1}{c}{ Catalyst } & \multicolumn{1}{c}{ Raw material } & $\mathrm{Ea}(\mathrm{kJ} / \mathrm{mol})$ & Alcohol solvent & Ref \\
\hline $\begin{array}{l}\text { Nanocomposites of } \\
\text { cellulose-Fe } \mathrm{O}_{4}\end{array}$ & $\begin{array}{l}\text { Oleic acid from } \\
\text { coconut oil }\end{array}$ & 16.56 & Methanol & This work \\
\hline $\mathrm{Al}-\mathrm{Sr}$ nanocatalysts & $\begin{array}{l}\text { BCO from sunflower } \\
\text { oil }\end{array}$ & 72.86 & Methanol & $\begin{array}{c}\text { Feyzi et al. } \\
(2017)\end{array}$ \\
\hline $\mathrm{CaO}$ nanoparticles & $\begin{array}{l}\text { BCO from Bombax } \\
\text { ceiba oil }\end{array}$ & 35.99 & Methanol & $\begin{array}{c}\text { Hebbar et al. } \\
(2018)\end{array}$ \\
\hline
\end{tabular}


Table 1 shows that catalysis using a nanocomposite of biopolymer cellulose impregnated with nanomagnetite $\mathrm{Fe}_{3} \mathrm{O}_{4}$ can reduce the activation energy; in comparison, Feyzi and Shahbazi (2017) obtained an activation energy of $72.86 \mathrm{~kJ} / \mathrm{mol}$ and Hebbar et al. (2018) one of $35.99 \mathrm{~kJ} / \mathrm{mol}$. Subsequently, the results of this study show good catalytic activity and the product can be used as a green biocatalyst in the future.

\section{CONCLUSION}

A cellulose-nanomagnetite $\mathrm{Fe}_{3} \mathrm{O}_{4}$ nanocomposites was successfully synthesized, as evidenced by the FTIR, XRD, SEM and TEM characterization, which revealed that nanomagnetite $\mathrm{Fe}_{3} \mathrm{O}_{4}$ had impregnated the acetylated nanocellulose as the support material. Nanomagnetite $\mathrm{Fe}_{3} \mathrm{O}_{4}$ with an average size of $30 \mathrm{~nm}$ in the nanocomposites was obtained. The nanocellulose- $\mathrm{Fe}_{3} \mathrm{O}_{4}$ nanocomposites was applied as a catalyst for the synthesis of methyl esters from oleic acid. A molar ratio of methanol to oleic acid of $3: 1$, catalyst amount of $1.5 \mathrm{wt} \%$, reaction time of 5 hours and reaction temperature of $60^{\circ} \mathrm{C}$ were employed as the optimum reaction parameters, with a conversion yield of $89.21 \%$. The type of methyl ester formed as the product of the GC-MS characterization was 9-octadecenoic acid methyl ester, with a relative molecular mass of 296.1 $\mathrm{g} / \mathrm{mol}$. In the kinetics study, a low activation energy of $16.56 \mathrm{~kJ} / \mathrm{mol}$ was obtained. The synthesis of biopolymer cellulose-magnetite nanocomposites using nanocellulose from rice husks with $\mathrm{Fe}_{3} \mathrm{O}_{4}$ nanoparticles can therefore be used as an effective catalyst for biodiesel synthesis from fatty acids such as vegetable oil.

\section{REFERENCES}

Arantes, A.C.C., Almeidaa, C.d.G., Dauzacker, L.C.L., Bianchia, M.l., Wood, D.F., Williams, T.G., William J. Orts, W.J., Tonolic, G.H.D., 2017. Renewable Hybrid Nanocatalyst from Magnetite and Cellulose for Treatment of Textile Effluents. Carbohydrate Polymers, Volume 163, pp. 101-107

Caetano, C.S., Caiado, M., Farinha, J., Fonseca, I.M., Ramos, A.M., Vital, J., Castanheiro, J.E., 2013. Esterification of Free Fatty Acids Over Chitosan with Sulfonic Acid Groups. Chemical Engineering Journal, Volume 230, pp. 567-572

Cercado, A.P., Ballesteros, F.C., Capareda, S.C., 2018. Biodiesel from Three Microalgae Transesterification Processes using Different Homogenous Catalysts. International Journal of Technology, Volume 9(4), pp. 645-651

Climent, M.J., Corma, A., Iborra, S., 2012. Homogeneous and Heterogeneous Catalysts for Multicomponent Reactions. RSC Advances, Volume 2(1), pp. 16-58

Colombo, K., Ender, L., Barros. A.A.C., 2017. The Study of Biodiesel Production using $\mathrm{CaO}$ as a Heterogeneous Catalytic Reaction. Egyptian Journal of Petroleum, Volume 26(2), pp. 341-349

Degife, W., Ashenafi, M., Thiyagarajan, R., Sahu, O., 2015. Extracted Biodiesel as Feed for Internal Combustion Engine. Journal of Mechanical Design and Vibration, Volume 3(1), pp. 1-7

El-Nahas, A.M., Salaheldin, T.A., Zaki, T., El-Maghrabi, H.H., Marie, A.M., Morsy, S.M., Allam, N.K., 2017. Functionalized Cellulose-magnetite Nanocomposite Catalysts for Efficient Biodiesel Production. The Chemical Engineering Journal, Volume 322, pp. 67180

Eyley, S., Thielemans, W., 2014. Surface Modification of Cellulose Nanocrystals. Nanoscale, Volume 6, pp. 7764-7779

Fatona, A., Berry, R.M., Brook, M.A., Moran-Mirabal, J.M., 2018. Versatile Surface Modification of Cellulose Fibers and Cellulose Nanocrystals through Modular Triazinyl Chemistry. Chemistry of Materials, Volume 30(7), pp. 2424-2435 
Feyzi, M., Shahbazi, Z., 2016. Preparation, Kinetic and Thermodynamic Studies of Al-Sr Nanocatalysts for Biodiesel Production. Journal of the Taiwan Institute of Chemical Engineers, Volume 71, pp. 145-155

Habibi, Y., 2014. Key Advances in the Chemical Modification of Nanocelluloses. Chemical Society Reviews, Volume 43(5), pp. 1519-1542

Hebbar, H.R.H., Math, M.C., Yatish, K.V., 2018. Optimization and Kinetic Study of CaO Nanoparticles Catalysed Biodiesel Production from Bombax Ceiba Oil. Energy, Volume 143, pp. 25-38

Helmiyati., Saefumillah, A., Yulianti, W., 2014. Synthesis and Swelling Kinetics of Superabsorbent Rice Straw Cellulose Graft Copolymers. Asian Journal of Chemistry, Volume 26(21), pp. 7337-7342

Helmiyati., Abbas, G.H., Kurniawan, S., 2017. Superabsorbent Nanocomposite Synthesis of Cellulose from Rice Husk Grafted Poly (Acrylate Acidco-Acrylamide)/Bentonite. In: Journal of Physics, IOP Conference, Materials Science and Engineering, Volume 188(1)

Hidayat, A., Mukti, N.I.F., Handoko, B., Sutrisno, B., 2018. Biodiesel Production from Rice Bran Oil over Modified Natural Zeolite Catalyst. International Journal of Technology, Volume 9(2), pp. 400-411

Jabasingh, S.A., Lalith, D., Prabhub, M.A., Yimam, A., Zewdu, T., 2016. Catalytic Conversion of Sugarcane Bagasse to Cellulosic Ethanol: $\mathrm{TiO}_{2}$ Coupled Nanocellulose as an Effective Hydrolysis Enhancer. Carbohydrate Polymers, Volume 136, pp. 700-709

Lavoine, N., Desloges, I., Dufresne, A., Bras, J., 2012. Microfibrillated Cellulose - Its Barrier Properties and Applications in Cellulosic Materials: A Review. Carbohydrate Polymers, Volume 90(2), pp. 735-764

Mendonça, I.M., Orlando, A.R.L., Paes, O.A.R.L., Maia, J.S., Mayane, P.S., Almeida, R.A., Silva, C.C., Duvoisin, S., de Freitas, F.A., 2019. New Heterogeneous Catalyst for Biodiesel Production from Waste Tucumã Peels (Astrocaryum Aculeatum Meyer): Parameter Soptimization Study. Renewable Energy, Volume 130, pp. 103-110

Sabaqian, S., Nemati, F., Heravi, M.M., Nahzomi, H.T., 2016. Copper(I) Iodide Supported on Modified Cellulose based Nano Magnetite Composite as a Biodegradable Catalyst for the Synthesis of 1,2,3 Triazoles. Applied Organometallic Chemistry, Volume 31(8), pp. 1-12

Santos, E.M., Teixeira, A.P.C., da Silva, F.G., Cibaka, T.E., M.H., Araujo, M.H., Oliveira, W.X.C., Medeiros, F., Brasil, A.N., de Oliveira, L.S., Lago, R.M., 2015. New Heterogeneous Catalyst for the Esterification of Fatty Acid Produced by Surface Aromatization/Sulfonation of Oilseed Cake. Fuel, Volume 150, pp. 408-414

Sun, S., Zhang, G., Ma, C., 2016. Preparation, Physicochemical Characterization and Application of Acetylated Lotus Rhizome Starches. Carbohydrate Polymers, Volume 135, pp. 10-17

Ummartyotin, S., Manuspiya, H., 2015. A Critical Review on Cellulose: From Fundamental to an Approach on Sensor Technology. Renewable and Sustainable Energy Review, Volume 41, pp. 402-412

Veillette, M., Giroir-Fendler, A., Faucheux, N., Heitz, M., 2017. Esterification of Free Fatty Acids with Methanol to Biodiesel using Heterogeneous Catalysts: From Model Acid Oil to Microalgae Lipids. Chemical Engineering Journal, Volume 308, pp. 101-109

Wanrosli, W.D., Zainuddin, Z., Ong, P., Rohaizu, R., 2013. Optimization of Cellulose Phosphate Synthesis from Oil Palm Lignocellulosics using Wavelet Neural Networks. Industrial Crops and Products, Volume 50, pp. 611-617

Zarei, S., Niad, M., Raanaei, H., 2017. The Removal of Mercury Ion Pollution by using $\mathrm{Fe}_{3} \mathrm{O}_{4}$ Nanocellulose: Synthesis, Characterizations and DFT Studies. Journal of Hazardous Materials, Volume 344, pp. 258-273 